\title{
Necessary Measures to Control Pathogenic Pests
}

\author{
Sindab Sami Jassim AL-Dahwi ${ }^{1}$, Hala Kadhem Jbir AL-Jboori ${ }^{1}$ \\ ${ }^{1}$ Scholar Researchers, Plant Protection Dept., College of Agricultural Engineering Sciences, University of \\ Baghdad, Iraq
}

\begin{abstract}
The measures necessary to control disease-causing pests in Iraqi environments need a lot of attention and care, and these measures take many forms and methods and due to the importance of this topic and its direct relationship to human health, it was appropriate to provide this service according to the integrated pest management system. When implementing the necessary measures to control pests, all domestic and international laws and policies must be complied.
\end{abstract}

Keywords: Necessary measures, pathogenic, pests

\section{Introduction}

The medical significance of pathogenic lesions: Arthropods and other animals affect human and animal health in various ways: First: As direct agents of disease or discomfort: 1 - Anxiety or dread about pests, pest phobia: the crawling or passing of a small insect on the face or any part of the body or its flight close to it may cause anxiety, annoyance or fear, and then it is called "Entomophobia" where a mental and mental disorder occurs in a person It may develop into a neurological disorder ${ }^{[1]}$. 2 - Annoyance and blood loss: The mere humming of mosquitoes may deprive some people of sleep despite their ability to sleep in very noisy places, and the disgust of some people is a result of the unpleasant odors that they secrete or the residues that they leave in places visited by pests such as cockroaches and rodents ${ }^{[2]}$. 3- Accidental injury to sense organs: As in an old needle insect that may enter the ears, or some nymphs of ticks can enter the ear of the sleeper and cause severe pain. And some fly larvae may enter the genital openings of children when they are not covered during sleep, ${ }^{[3]}[.4$ - Allergy: Some people show high sensitivity as a result of the formation of certain proteins, especially among those working in museums or apiaries, and it is the result of stinging, inhalation, or contact with insect feces, or their shedding skin, or parts of their bodies. Allergy is of two types: The first type is caused by inhaling the smells of the feces of the lesion or powder from the bodies and scales of the lesions and appears as a result of the presence of cells called Allergens in the respiratory system, causing a type of cough, shortness of breath and asthma, ${ }^{[4]}$. The second type is caused by the toxic proteins that the toxins contain in some insects, which push the body to form antibodies,

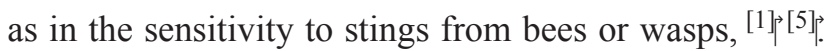
5 - Envenomization: The pest secretes toxins that are injected into humans or animals and cause severe pain or damage that may reach death. The toxin injection process is carried out in several ways, including [1] [2] [6]:

By the bite: As in the case of the Assassin bugs or the female Black Widow Spider, which secretes a toxin in the wound that causes painful irritation?

By stinging, as in bees, wasps, wasps, and some ants and scorpions, and at the end of the abdomen of these pests there is a stinging machine that they use to bite what annoys them or attacks their nests. 

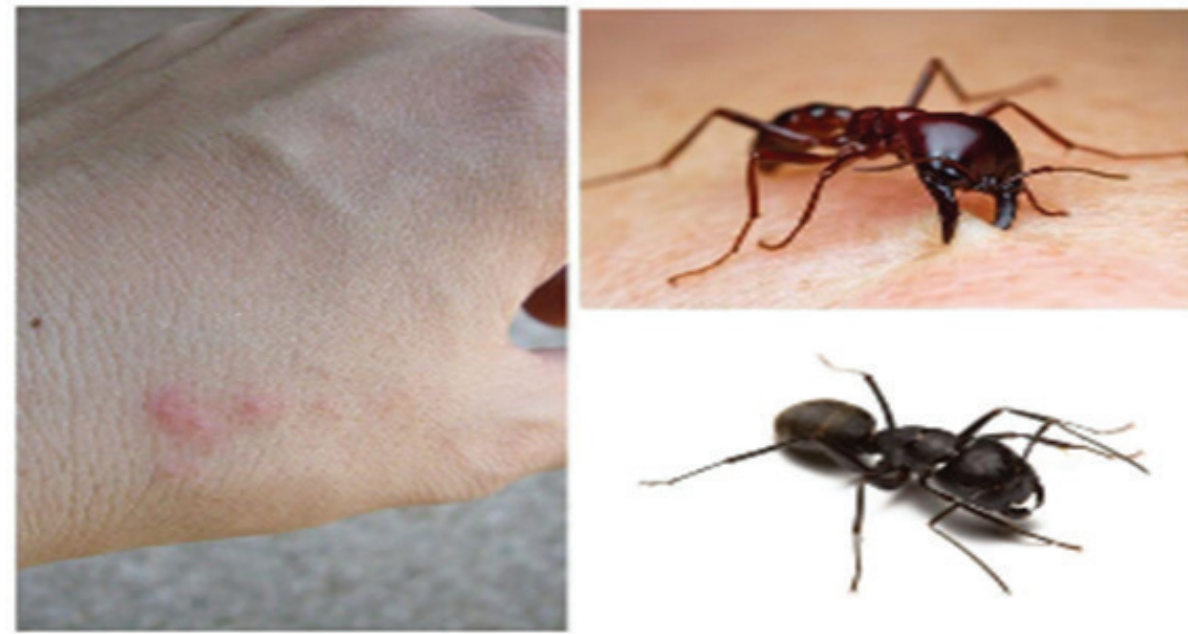

Fig -1: Note of an ant biting one of the victims.

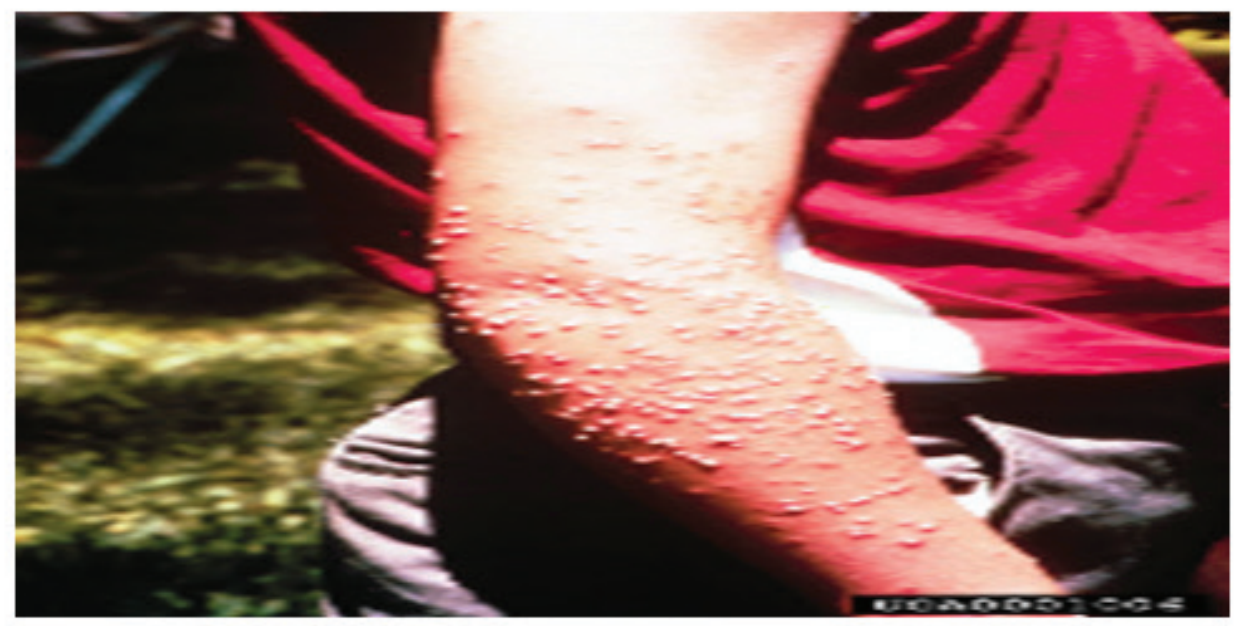

Fig -2: Symptoms of fire ant sting.

The secretion of inflammatory fluids to the healthy skin, as in some types of red-burning ants, which secrete formic acid as a spray on the enemies.

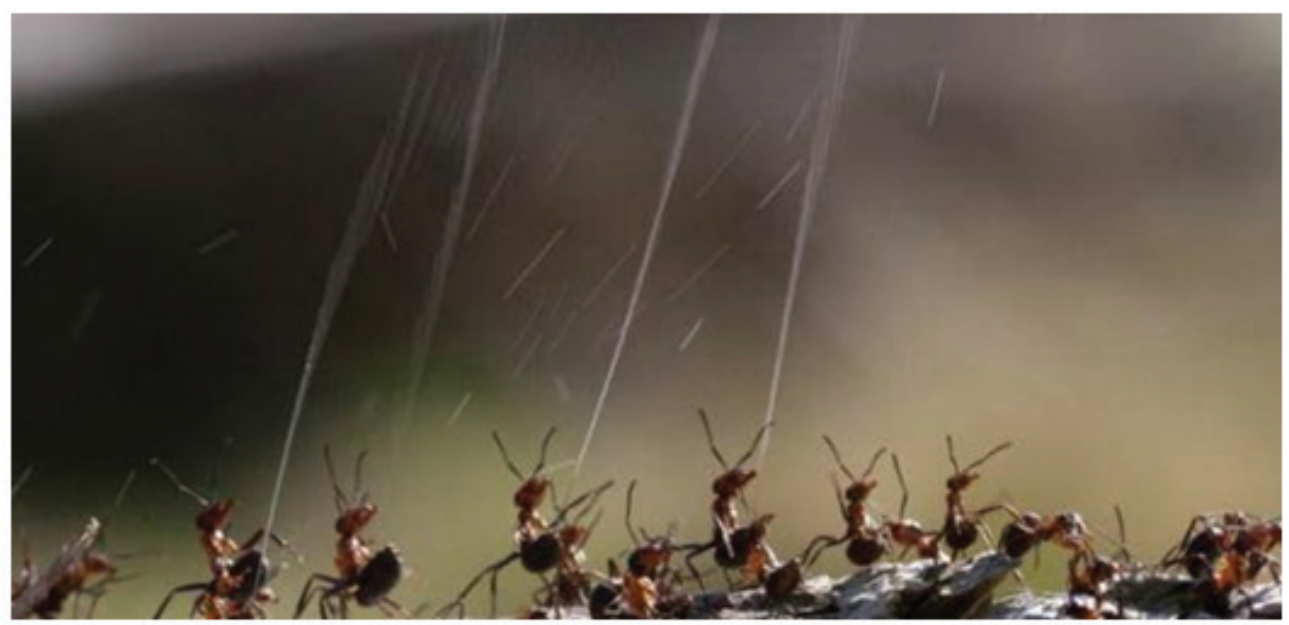

Fig -3: Formic acid is released by the red ant when Confronting the enemy. 


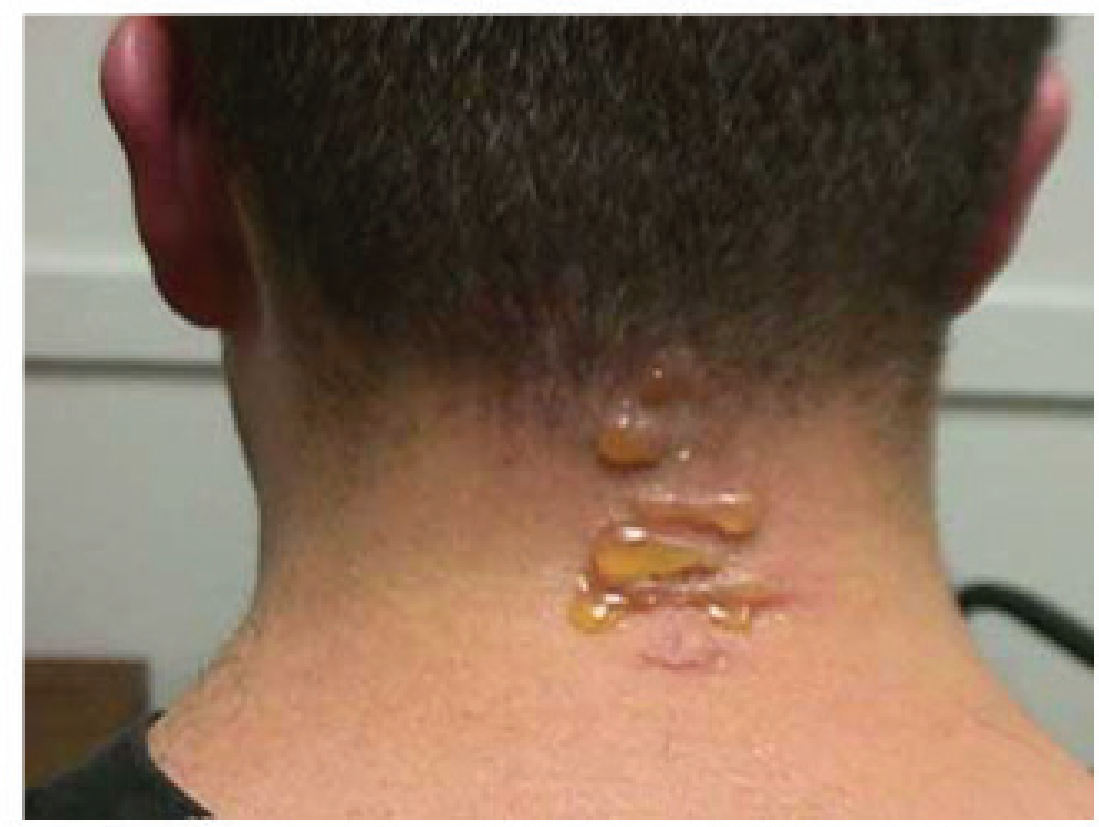

Fig -4: Formic acid is sprayed on the back of the neck t?

By contact: like the blister beetles, they cause an irritating effect if they touch the skin of a human or animal ?.

6- Dermatosis: they occur in two ways: The first method is a result of external intrusion on the human body and its bite, so it absorbs its blood, which results in serious diseases such as sucking lice, bed bugs and fleas, ${ }^{[7]}$.

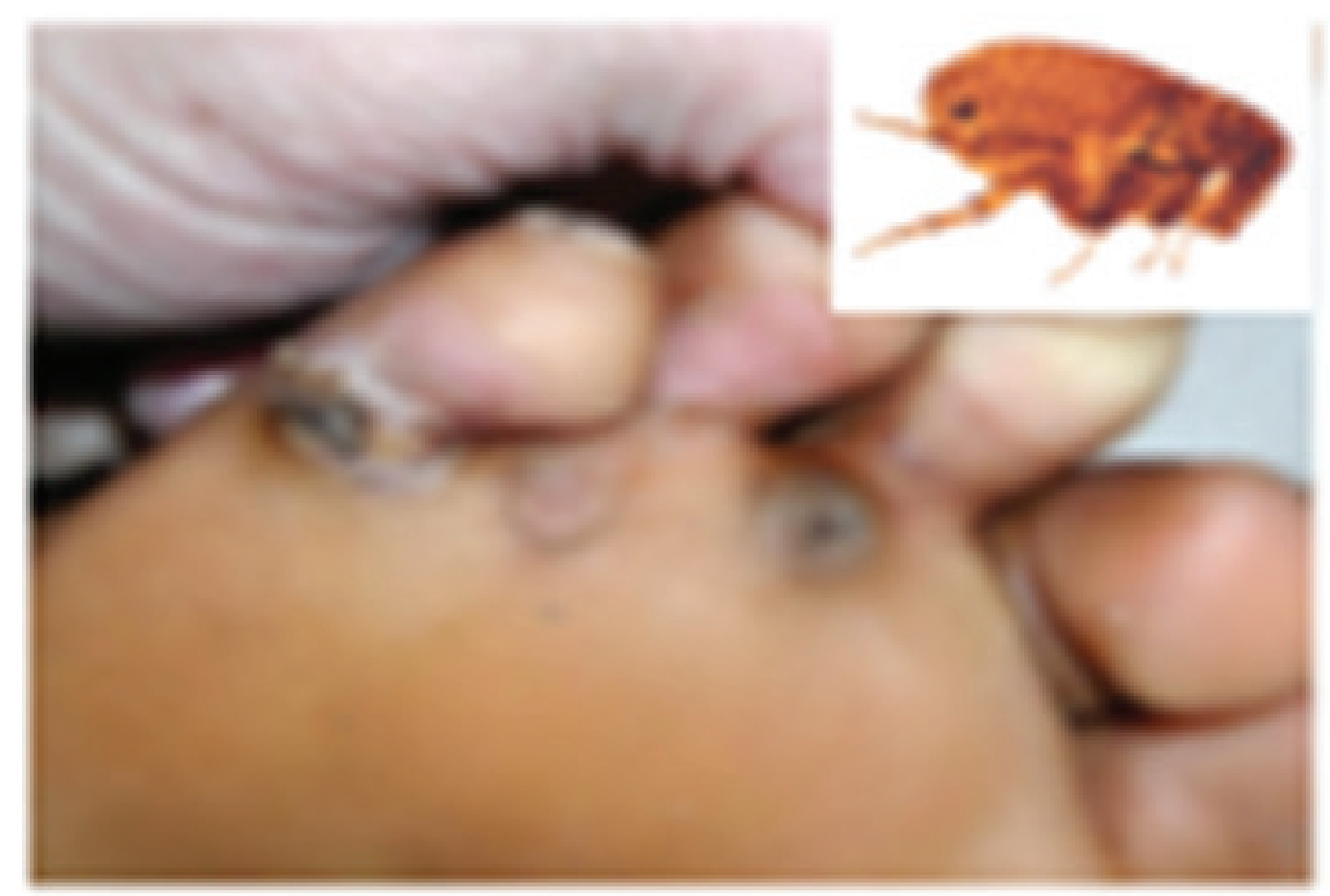

Fig -5: Flea and skin infections caused by bed bugs 


\section{Head lice}

\section{Pediculus humanus capitis}

\section{Body lice Pediculus humanus corporis}

: Trench Fever It may be called a fever Caused by bacteria Rickettisa Quintana, Lice transmit them with blood or feces

\section{Relapsing Fever}

The cause of the disease is similar to bacteria and it is called Spirochaeta recurrentis. It is transmitted by lice while feeding on human blood and causes an increase in body temperature, which occurs in people who are always infected, ${ }^{[7]}$ ?

The second method: as a result of attacking the tissues of the human body, as in mosquitoes and other types of mites where they dig tunnels inside the skin causing severe infections, as in the Scabies Mites (Scabies Mites: Sacoptes scabiei) that causes cases of scabies Acariasis ${ }^{\left[{ }^{[8]}\right.}$.

Examples of the life cycle of some pathogenic pests and the appropriate measures needed to control them without harm the environment

\section{Flies}

Phylum: Arthropoda

Class: Insecta

Order: Diptera

Family: Muscidae

Musca domestica

Family: Sarcophagidae

Sarcophaga carnaria

Family: Calliphoridae

Calliphora vicina

Family: Phlebotominae

Phlebotomus papatasi, ${ }^{[1]}$.

Habitat:

The breeding centers for flies are the place of waste, containers, animal pens, natural fertilizers and other places where organic waste collects, ${ }^{[1]}{ }^{[9]}$.

\section{Living and Nutrition:}

Both sexes (male and female) feed on sugar secretions, decomposed organic waste and dirt, and the larvae feed on leftovers in the garbage and decomposing corpses where they live, ${ }^{[2]}$ ?

Life Cycle: The life cycle of flies passes through four roles (egg - larva - pupa - adult). The female lays her eggs in decomposing organic matter as well as in litter and dirt, which hatch from the worm-shaped larvae that have no legs, which in turn into pupa from which the adult stage of flies emerges After that, the adult stage produces about ten generations during the year, and is active throughout the year and lasts for a life cycle of 8-30 days, depending on the availability of appropriate conditions, ${ }^{[9]}$.

\section{Measures to control flies ${ }^{[1][2][9]}$ :}

\section{1- Integrated control of larvae of flies}

$\S$ Preventive control: One of the best control methods is to completely eliminate places of reproduction and pay attention to cleanliness, and it is summarized as follows:

$\S \quad$ Not leaving food and vegetable remains exposed to reduce the formation of foci for laying fly eggs.

$\S$ Emphasizing that containers are free of waste, that they do not accumulate for periods of more than (12) hours, and that they are properly disposed of immediately.

$\S \quad$ Use containers with a lid so that it is closed well after putting garbage bags in it and so as not to help the reproduction of flies.

$\S$ Disposal of slaughterhouse waste in a healthy and sound manner that is not a fertile environment for flies to breed.

\section{Chemical control:}

- If the containers cannot be emptied during the 12- 
hour period, they are sprayed with lime chlorine powder (calcium hypochlorite $35 \%$ or $65 \%$ ).

- Spraying empty containers before distribution and after emptying them with suitable organophosphorous pesticides mixed with Citronella oil (to reduce their odors).

- The use of spraying with larger particles using MIST BLOWER devices, as it left a layer of the pesticide on the target surfaces to combat the adult stages of the flies in public places.

- Periodically spraying the waste disposal sites with the recommended pesticides to prevent the reproduction of fly larvae.

\section{Integrated control of the adult stage of flies:}

\section{2-1: mechanical control of flies}

Coating the containers with lubricant materials that do not interact with liquids, in order to ensure the ease and speed of emptying the containers, as well as their cleanliness of any residues that may stick to them.

Emphasizing the existence of a sufficient number of electrical and pheromone traps to control the extreme stages of flies in public health stores.

- The use of adhesive tapes in restaurants and supermarkets to combat the adult phases of flies, provided that they are placed out of sight of consumers and replaced daily to reduce densities.

The use of adhesive tapes on the upper inner sides and frames of containers that work to enhance the attraction of flies to them or get rid of them after gathering on these tapes inside the container.

\section{2-2 Biological control of flies}

Using pheromone traps, as they contain an attractive substance that attracts large numbers of flies $(5 ; 6 ; 10)$.

\section{2-3: Chemical control of flies}

- Using baits in markets, slaughterhouses, and waste places.

- The use of tapes impregnated with pesticides.
- Use of the safest pesticides to control the adult stages of flies in places of rest and gatherings by using vacuum spraying with ULV micro-spray devices in places where flies gather in the early morning .

\section{Cockroaches: Cockroach}

Kingdom: Animalia

Phylum: Arthropoda

Class: Insecta

Order: Blattodea

1- Family: Ectobiidae

1- Supella Longipala Brown striped cockroach

2- Parcoblatta pensylvanica Cockroach wood

2- Family: Blattellidae

1- Periplaneta Americana American cockroach

2- Blattella orientalis Oriental cockroach

3- Blattella germanica German cockroach

Habitat:

The order of cockroaches includes many famous numbers, including (the American cockroach, the German cockroach, the oriental cockroach, the Australian cockroach, the Egyptian cockroach and the brown belt cockroach) and it is called a household pest because it lives near a person in his home, in the kitchen, the restaurant, the store, the sanitary facilities, the sinks, and behind the water pipes, And in the food preparation and storage rooms, in clubs, cinemas, cafes, and other different stores that are close to a person or his place of residence, ${ }^{[1][2]}$.

Life cycle: Insects with a gradual incomplete development, that is, they go through three roles (egg - nymph - adult). The eggs are placed in groups in a special protective bag called the egg sac, and this bag either remains attached to the end of the abdomen in the female or is placed in appropriate places, and sometimes the eggs remain Inside the female, then the female gives birth to nymphs, and the incubation period for eggs varies according to species and according to temperature 
and environment, $[10]$

\section{Reasons that lead to an increase in cockroaches ${ }^{[1]}$ [5]:}

1. The presence of food leftovers inside the kitchen.

2. The accumulation of waste inside and outside the home (it has been proven to scientists that this insect does not stay long in clean homes).

3. The cockroach insect activity increases in dark and damp places, especially in rooms and homes that suffer from leakage of drinking water and sewage water

4. The presence of cracks in the walls and floors of old houses and buildings, as this insect moves from one building to another by this method,

Procedures for controlling cockroaches ${ }^{[9]}$ : The integrated pest management program includes the following:

$\S$ Monitoring the possible places of infection before carrying out the treatment to know the type of pest and the places of infection.
$\S \quad$ Follow up the affected places after the treatment to see the success of the used control method.

$\S \quad$ The use of multiple means in the control to put the cockroach's problem under control, such as:

1- Preventing the introduction of the pest and following good hygienic methods (constant and careful cleaning, taking care to raise garbage regularly and put it in special waste bags that are closed tightly).

2- Treating cracks and holes in building walls, especially in sewer openings, and repairing water pipes to prevent moisture.

3- Taking care of foodstuff stores and using the correct preservation method.

4- Putting sticky and attractive traps for cockroaches, or using electric traps, using insect growth regulators, using low-toxic "public health" insecticides, using boric acid powder in wet places where cockroaches live. This acid affects as a slow-acting infectious poison and has no toxic effect on animals, it is also characterized by being a repellent to cockroaches, which gives it a great scope for use as food bait.

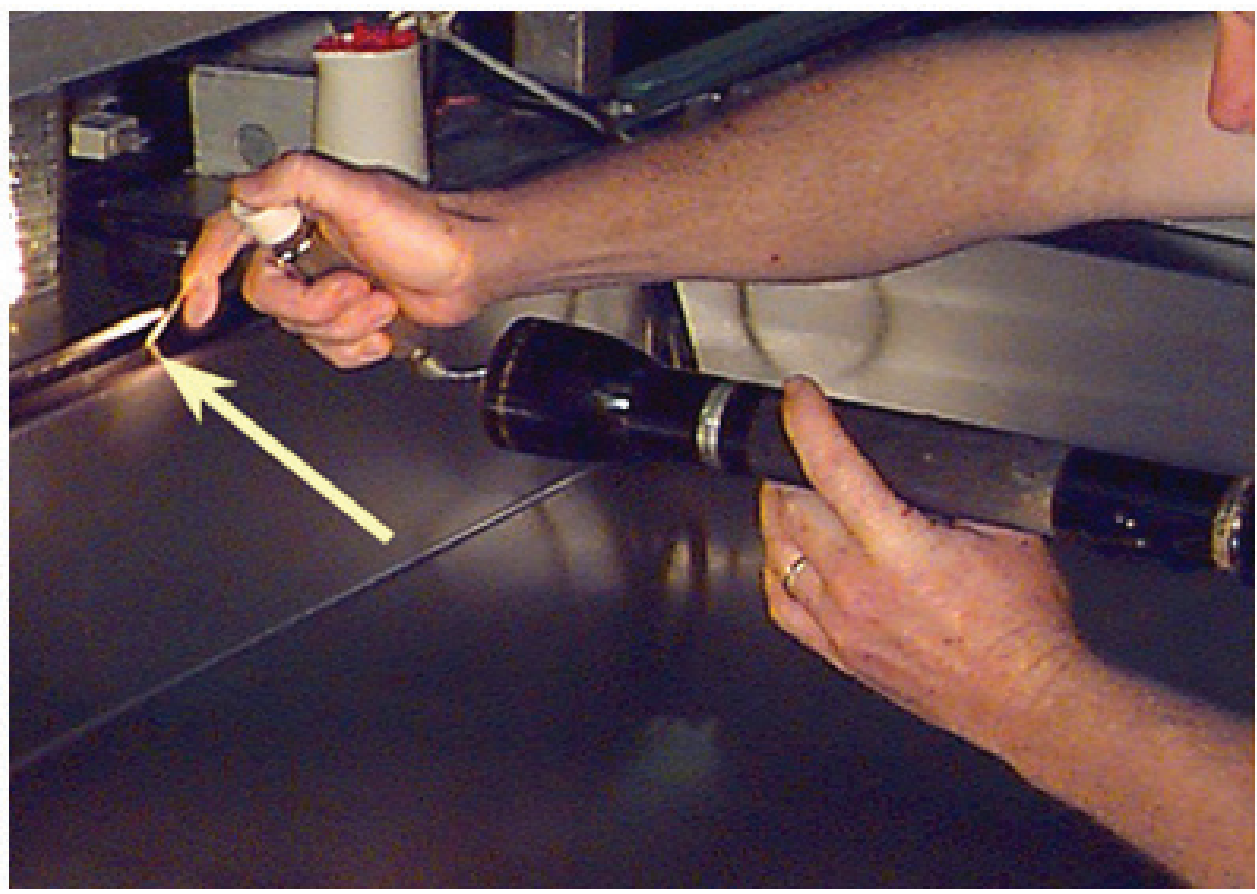

Fig -6: Treating cracks and holes and treating stains in The chemical control of cockroaches. 


\section{$\underline{\text { Scabies mite classification }}$}

Kingdom:Animalia

Phylum: Arthropoda

\section{Class: Arachnida}

Subclass: Acari

Order: Sarcoptiformes

Family: Sarcoptidae

\section{Genus: Sarcpotes}

\section{Species: scabiei}

This type Sarcoptes scabiei attacks both humans and mammals (dogs, horses, mules, donkeys, goats, sheep and rodents). Each type of scabies mite specializes in a host that causes it to have scabies, itching and skin infections, and the infection is transmitted from person to person, from animal to person and from human to animal, ${ }^{[6]}[8]$.

Life cycle and nutrition of a human scabies (Sarcoptes scabiei var. hominis hering) ${ }^{[1][6][8]}$ : Its life cycle takes between (10-19) days and may exceed that in some species to reach a month, and adult female can live for (70) days. The female digs tunnels in the skin a depth of one centimeter or more to lay eggs and feed on dead skin cells and secretions of live skin. She does not use human skin except as a container to incubate her eggs - and the eggs remain in these tunnels, for a period ranging between (10-17) days. The human skin injury may last for more than a month, but the sensation of severe skin irritation begins after this period, especially at night.

They lay between (60-100) eggs in the last five weeks of their life. After 3-7 days the eggs hatch to larvae with three pairs of legs and leave the tunnel and dig another tunnel (surface pocket) in the stratum carenum and then they moult into nymphs and become adult mites after approximately three weeks in the same place. Males and females mate, and the fertilized female leaves and digs another tunnel to lay her eggs,
Protection, ${ }^{[2]}{ }^{[7]}$ :

$\mathrm{v}$ It is necessary to ventilate the bedrooms and work on exposing the pillows and blankets to direct sun whenever possible and for the longest possible period.

$\mathrm{V}$ It becomes necessary in hospitals for the patient to use his own pillows and change the bed linen on a daily basis, as it is one of the most popular ways of transmitting infection due to the difficulty of periodically disinfection, as it is public places that the patient uses after another.

v Using the artificial sun in the event that the sun does not enter the dwelling by purchasing a set of lamps (ultraviolet and infrared rays, while operating them in closed rooms, and this greatly contributes to reducing the number of Mites.

Treatment ${ }^{[1][6]}$ : The treatment aims to finally get rid of the parasites that cause the disease, therefore all individuals in the home must be treated to prevent spread or recurrence by using materials that eliminate parasites and be in the form of topical paints and are the following alternatives:

$\S$ Benzyl Benzoate $25 \%$ solution. Apply the entire skin of the body from the neck to the feet before going to sleep daily for 3 days.

$\S$ Cream permethrin (Permethrin 5\%). Apply the whole body well before sleeping, from the neck to the feet, between the fingers and in the folds of the skin, and leave it for 8 - 14 hours (until the morning), then wash the body well. And it is used in this way for a week. It is preferable that the skin be dry before treatment.

$\S$ As for children, it is preferable to use sulfur preparations such as $10 \%$ sulfur gel. And recovery takes place within 4 weeks of treatment, and it should be noted that the itching can continue for weeks after eliminating the parasites.

\section{Conclusion}

Measures to be taken when implementing the control program:

$\mathrm{V}$ Identify the types of pathogenic pests. 
$\mathrm{v}$ Identify the characteristics of the pest such as (habits, life cycle, needs and hates of the pest).

v Take rapid steps to exclude the pest from the area if possible.

$\mathrm{v}$ Determine the ways of entering the pest to a site and its hiding places.

v Availability of all means and tools with the work team before starting the implementation of the control program.

\section{Conflict of Interest: None}

\section{Funding: Self}

Ethical Clearance: Not required

\section{References}

1. Al-Hajj IAY, Dabdoub BR. School insect pests. Iraq. Ministry of Higher Education and Scientific Research. University of Al Mosul. 2014;p120.

2. Integrated Management of Public Health Pests. Kingdom of Saudi ßArabia - Ministry of Municipal and Rural Affairs - Ministry Agency for Municipal Affairs, General Administration of Public Health, 2016.

3. Clercq P, Mason PG, Babendreier D. Benefits and risks tof exotic biological control agents. BioControl»2011; 56 (4): 681-698.

4. Downs A M R, Harvey I, Kennedy CTC. The epidemiology of head lice and scabies in the UK.
Epidemiol. Infect. 1999; 122: 471ґ77.

5. Mansor MS, Al-Mallah NM. Effect of Sub-Lethal dose of Some Insect Growth Inhibitors on Some physical features of Wings icuticle of «Amercinca Cockroach Periplaneta americana. The Iraqi Journal of ¡Agricultural Science, 2017 ;48 (5):12551262].

6. Al-Wakil MA. Prevention and treatment of mite (acarus - scab) dust attacking humans. Editor-inchief of the Journal of Environmental Sciences and Technology, 2013.|"

7. Food and Agriculture Organization of the United Nations. FAO The International Code of Conduct on the Distribution and Use of Pesticides for Guidelines for the Prevention and Management of Resistance to Pesticide Action. 2012; Pp’73.

8. Hamad S K, Mawloud NAQ. Epidemiological study of the human experiment mite parasite Sarcoptes scabiei var. Hominis Hering lamong the patients arriving at the Dermatology Department at Rizkari Hospital in Erbil / Kurdistan Region / Iraq, 2016

9. AGP - Integrated Pest Management.Best Home Remedies To Kill And Control Cockroaches Catnip. HRT.whw1.com. Retrieved 19 August 2012. $\$$

10. Jihad IS, Ridh BA. The reality of Some Specialized Tasks iof Human Resources Management in Agricultural Extension System in Middle Region Provinces of Iraq. The Iraqi Journal of Agricultural |Sciences, 2017;48(1): 310-324." 